REALA, número 14, octubre de 2020

Sección: ARTÍCULOS

Recibido: 11-06-2020

Modificado: 05-10-2020

Aceptado: 05-10-2020

DOI: https://doi.org/10.24965/reala.i14.10808

Páginas: 49-68

\title{
Repensar la acción pública local desde nuevos modelos de gestión administrativa
}

\section{Rethinking local public action from new administrative management models}

\author{
María Rosario Alonso Ibáñez \\ Universidad de Oviedo (España) \\ ORCID: https://orcid.org/0000-0001-9223-9294
}

mralonso@uniovi.es

\begin{abstract}
NOTA BIOBRÁFICA
Catedrática de Derecho Administrativo de la Universidad de Oviedo. Desarrolla su actividad investigadora en materia de urbanismo, territorio y patrimonio cultural. Responsable del grupo de investigación interdisciplinar Estudios Jurídico-Sociales sobre Territorio y Desarrollo Urbano Sostenible-GTDS y de la Red Temática sobre Desarrollo Urbano- URBAN RED.
\end{abstract}

\section{RESUMEN}

Resulta imprescindible reubicar a las Administraciones públicas en el escenario de cambios y decrecimiento económico que caracterizan a la sociedad actual y redefinir la acción pública local mediante el fortalecimiento de la capacidad institucional y de la capacidad de autogobierno de la autonomía local. Estas capacidades son necesarias para adaptar dicha acción a los nuevos modelos de gestión pública urbana promovidos por la Unión Europea en torno al cada vez más consolidado modelo de desarrollo sostenible e integrado. Este trabajo pone en valor el componente político de la autonomía local para reivindicar un nuevo modelo de acción local, adaptada a las dimensiones sustantiva y metodológica de la sostenibilidad.

\section{PALABRAS CLAVE}

Acción pública local; gestión pública; autonomía local; capacidad institucional; desarrollo sostenible.

\begin{abstract}
It is essential to relocate public administrations in the scene of change, and economic decline that characterize contemporary society and redefine the local public action through the strengthening of institutional and self-government capacity. This capacity is necessary to adapt this action to the new urban public management models promoted by the European Union around the increasingly consolidated model of integrated and sustainable development. This paper highlights the political component of local autonomy to claim a new model of local action, adapted to the substantive and methodological dimensions of sustainability.
\end{abstract}

\section{KEYWORDS}

Local public action; public management; local autonomy; institutional capacity; sustainable development. 
REALA. Nueva Época - N.o 14, octubre 2020 - ISSN: 1989-8975 - DOI: https://doi.org/10.24965/reala.i14.10808 - [Págs. 49-68]

Repensar la acción pública local desde nuevos modelos de gestión administrativa

María Rosario Alonso Ibáñez

\begin{abstract}
SUMARIO
INTRODUCCIÓN. 1. LA TRANSFORMACIÓN DE LA ACCIÓN PÚBLICA LOCAL Y LA DIMENSIÓN METODOLÓGICA DE LA SOSTENIBILIDAD URBANA. 2. HACIA LA SUSTANTIVACIÓN JURÍDICA DE UN NUEVO MODELO DE GESTIÓN LOCAL. 2.1. LA ESCALA ESPACIAL DE GESTIÓN: ÁREAS URBANAS FUNCIONALES. 2.2. LA ESCALA ORGANIZATIVA: AUTORIDADES URBANAS. 3. FORTALECIMIENTO DE LAS CAPACIDADES INSTITUCIONALES. 3.1. LIMITACIONES DERIVADAS DEL RÉGIMEN LOCAL. 3.2. LA CAPACIDAD DE AUTOADMINISTRACIÓN DE LAAUTONOMÍA LOCAL. CONCLUSIONES. REFERENCIAS BIBLIOGRÁFICAS.
\end{abstract}

\title{
INTRODUCCIÓN
}

Recobra un lugar preferente en la actualidad volver a pensar sobre el papel del Estado, sus instituciones y administraciones públicas, sus modos de ejercer el poder para aportar a la sociedad seguridad institucional y jurídica en la construcción de progreso y desarrollo, desde los requerimientos de la sostenibilidad. El escenario de cambios en que nos ha colocado lo que probablemente sea la mayor crisis de la era moderna, generada en lo más inmediato por la pandemia covid-19 -en su versión más lenta, por lo que desencadena el calentamiento global-, no sólo está provocando un profundo impacto en los más preciados bienes de las sociedades actuales, como la vida, la salud, la estabilidad económica y el soporte laboral de las personas. Para las Administraciones públicas también, tan acostumbradas a la previsibilidad y a la estabilidad en su actividad ordinaria, pero llamadas a tener que adaptarse al cambiante entorno político, económico y social, en permanente evolución.

Los cambios sustanciales que se están produciendo en la funcionalidad de las instituciones públicas, y en la dinámica de la economía, no son nuevos. Veníamos asistiendo ya, casi de forma imperceptible, a la emergencia de un nuevo orden, y hoy es ya evidente que nada va a poder seguir igual al corto, medio y largo plazo. Ya no se cuestiona, por ejemplo, que los modelos de desarrollo y planteamientos económicos clásicos tengan que empezar a complementarse razonablemente con nuevos conceptos, valores y principios. El marco económico como factor determinante de desarrollo, identificado exclusivamente con crecimiento de renta, resultan claramente insuficientes porque el crecimiento económico no se traduce necesariamente en progreso social, y precisa registrar todos los cambios más significativos que se producen en el conjunto de la sociedad (Farinós, 2015: 63). Se precisa tomar en consideración, por ejemplo, la prestación de servicios básicos, o los niveles de desigualdad y pobreza, esto es, los fundamentos del bienestar y la calidad de vida.

De igual manera, desde hace unas décadas abundan también en la ciencia política las referencias a la crisis de los modos tradicionales de ejercer el poder público. Una serie de procesos de transformación de las estructuras socioeconómicas, de orden global, estarían «sometiendo a fuertes presiones de cambio las formas tradicionales de regulación del conflicto social, y con ello, favoreciendo la emergencia de paradigmas alternativos» (Blanco, 2012:17).

Y no otra cosa sucede al Derecho. La globalización ha acarreado la interdependencia de los sistemas jurídicos, la internacionalización de las fuentes, la homologación y armonización de reglas y estándares, inestabilidad, precariedad y desestructuración de las construcciones dogmáticas tradicionales, que pasan a ser frecuentemente deficientes. Para la dogmática jurídica no existe acuerdo sobre la extensión y límites de una nueva realidad que se ha dado en llamar «Derecho global», poniéndose en duda, con posicionamientos enfrentados, que todas las normas que resultan relevantes en esta realidad sean Derecho ${ }^{1}$. Precisamente, la regulación de la sostenibilidad urbanística, de igual manera que el de otros muchos fenómenos como el de la emergencia climática, de imposible reconducción a las lógicas jurídicas clásicas, caracterizados por la fragmentación en su normativización y el carácter eminentemente programático y principial de su tratamiento, ponen en entredicho el monopolio atribuido convencionalmente al Estado en la producción de los principios y reglas jurídicas.

En este escenario de cambios, retos y transformaciones, la necesidad de impulsar reformas administrativas que reorienten el papel de las Administraciones resulta claramente insuficiente si deja fuera el

1 El concepto de Derecho que manejan los autores que utilizan la expresión Derecho global «está lejos de resultar pacífico» (DARNACULLETA, 2016:11). Desde la perspectiva mayoritaria del positivismo jurídico, CASSESE ha reconocido que «Global administrative law is not only law, because it also includes many types of "soft law" and standards» (CASSESE, 2015: 466). En contra, Darnaculleta, aunque, como señala, comparte plenamente la visión conciliadora de este fenómeno propuesta por AUBY (2013). 
fortalecimiento de los distintos marcos jurídico-institucionales implicados. En este trabajo nos detendremos en el referido al gobierno y Administración local, recordando que la tendencia de las pretendidas reformas administrativas impulsadas en las dos últimas décadas, objetivamente necesarias, se han llevado a cabo sin los mínimos consensos y compromisos políticos básicos, y no han logrado revertir ya no los problemas profundos de base, sino mucho menos fortalecer a la Administración local como institución ${ }^{2}$, a su capacidad de acción pública. En paralelo, el régimen local precisa también reaccionar «mediante la teorización e innovación de sus herramientas clásicas, abriendo sus estructuras, adaptándolas y conectándolas con los datos y teorías científicas provenientes de otras disciplinas» (Simou, 2020: 74).

Las crisis suelen ser tradicionalmente ventanas de oportunidad para llevar a cabo reformas profundas. No ha sido así con lo que ha acontecido con el régimen local, que fue un ajuste fiscal más que otra cosa, empobreciendo y debilitando a la Administración local como institución. Aunque el deterioro venía ya produciéndose mucho más atrás en el tiempo, desde el momento en que no ocupó en el texto constitucional el lugar relevante que le corresponde, siendo parte como es de la arquitectura del Estado. Además de dejar relegada a un segundo plano la autonomía local, «tampoco midió bien la relación de la Administración local con el Estado y las Comunidades Autónomas, a lo que se suma el hecho de que la competencia sobre el régimen local sea compartida entre el Estado y la Comunidad Autónoma, que ha impedido una debida articulación entre las distintas instancias de poder» (Baño 2019: 12). Estado y Comunidades Autónomas, como es sabido, disponen de capacidad económica y de un conjunto de títulos competenciales que permitirían dejar de considerar al nivel local en un actor olvidado en la organización territorial del poder; pero vienen obviando que son gobierno y no solo Administración.

A falta de medidas serias para una reforma de la Administración y el régimen local, lo que sí ha ido cambiando son muchos elementos del «andamiaje administrativo». De forma silenciosa y casi espontánea se han ido produciendo transformaciones metodológicas que afectan a la gestión pública local, aunque «seguimos teniendo unas organizaciones públicas precarias en sus modelos» (Ramiò, 2016).

El debilitamiento institucional del gobierno y la Administración local a que nos referimos tiene su mayor repercusión allá donde los ciudadanos vivimos en colectividad, en las ciudades; o lo que es lo mismo, en el espacio urbanizado que el tipo de desarrollo urbano extensivo y fragmentado ha generado, de una escala muy superior y nunca conocida anteriormente, hasta llegar a encontrar que grandes ciudades engullan a las propias regiones, o que los territorios más transformados por la urbanización se estén convirtiendo en enormes tramas urbanas con dinámicas metropolitanas. Este espacio es el escenario en el que se ha desarrollado lo que se ha llamado una «nueva revolución urbana» ${ }^{3}$, y en el que más intensamente impactan las

2 Llevamos más de cuatro décadas a la espera de la gran revolución administrativa que tendría que haber conllevado lo que la Constitución de 1978 diseñó como modelo de federalismo colaborativo y plasmado en el Estado de las Autonomías. Desde el primer gran intento serio impulsado, pero no secundado, en 1988, hasta la creación de la Comisión para la Reforma de las Administraciones Públicas (CORA) por Acuerdo del Consejo de Ministros del 26 de octubre de 2012 para mejorar la eficiencia y eficacia de la actividad pública y su Informe presentado en Consejo de Ministros de 21 de junio de 2013 con un conjunto de 218 medidas dirigidas a la mejora y simplificación del funcionamiento de las administraciones públicas. Pasando por algún que otro proyecto autonómico, de entre los más conocidos el Informe de la Comisión para la Racionalización y Mejora de la Administración Pública (CORAME) de junio de 1994, que exponía 47 medidas para renovar la estructura organizativa del Gobierno y la Administración del País Vasco. Preciso es resaltar que la Administración Local está ausente en el Informe CORA, y que las sucesivas y mayores reformas del régimen local lo han sido vinculadas a coyunturas. Especialmente así aconteció con la reforma del año 2013, apresuradamente vinculada a una coyuntura de crisis económica, cuando en régimen local no puede regularse con este inoportuno e inadecuado planteamiento. Lo sintetiza JIMÉNEZ (2013: 2) cuando señala que «No nos merecemos una estructura institucional del gobierno local de tan baja calidad. La planta municipal es insostenible. El minifundismo municipal no puede dar respuesta a las necesidades de servicios públicos de calidad que tiene la ciudadanía. La provincia y, en particular, la mayor parte (que no todas) de las diputaciones provinciales son organizaciones con un bajo rendimiento institucional, carentes de legitimidad democrática directa y sin apenas vida institucional (el juego mayorías/minorías está prácticamente roto por la práctica del "regateo y el trueque" político). Las comarcas, allá donde existen, llevan una vida lánguida y buscan perennemente su sitio en competencia o concurrencia con las provincias. Mancomunidades las hay que funcionan, pero otras muchas no. De los consorcios otro tanto. Las entidades locales menores, que realmente no molestan o molestan poco, se han convertido en uno de "los malos de la película". Pero a pesar de esa necesidad objetiva de reformas, nadie quiere realmente cambiar nada. Las reformas institucionales en España se hacen habitualmente para que aparentemente cambien las cosas y realmente todas sigan igual. Son reformas falsas, de mentira, que en realidad a nadie engañan».

3 En expresión de BORJA (2011), en el sentido de una «revolución tecnológica vinculada a la emergencia de la sociedad informacional y de los impactos sobre el territorio debidos a los nuevos medios de información y comunicación. Una revolución económica producida por la globalización y por el carácter dominante del capitalismo financiero. Una revolución espacial por el tipo de desarrollo urbano extensivo y fragmentado que genera territorios urbanizados de una escala muy superior a las conocidas anteriormente. Una revolución sociocultural por la multiplicación de colectivos humanos muy heterogéneos y por una individualización de los comportamientos. Y una frustrada revolución política por la inadecuación entre los territorios como espacios socioeconómicos y los territorios institucionales». 
sucesivas crisis; mejor dicho, el deterioro que dejan sembrado, afectando a la mayoría de la población. Reubicar a las Administraciones públicas es este espacio resulta imprescindible. Y de paso, redefinir la acción pública local, entendida como lo hace la ciencia política, como «conjunto de dispositivos que permiten movilizar actores y recursos de forma estable, coordinando e integrando intervenciones diversas para alcanzar objetivos definidos colectivamente» (Pinson, 2011: 32). Ya lo ha destacado Velasco (2020: 23), «asumimos, al menos los iuspublicistas, que tenemos que prestar más atención a lo que nos dice la ciencia política, y en especial la ciencia de la Administración». Y en escenarios de crisis y decrecimiento económico como los presentes, donde el eje local-global, «pensar globalmente y actuar localmente», ha pasado a ser una cuestión de supervivencia, repensar la acción pública local desde la interdisciplinariedad resulta todavía más necesario, «profundizar en las relaciones interdisciplinares que permitan al Derecho administrativo construir sus categorías conceptuales y metodológicas con un mayor aporte de otras ciencias» (Marcheco, 2018: 23).

Es desde este planteamiento que nos referiremos a continuación a las capacidades de la Administración local para desarrollar nuevas políticas de ciudad.

\section{LA TRANSFORMACIÓN DE LA ACCIÓN PÚBLICA LOCAL DESDE LA DIMENSIÓN METODOLÓGICA DE LA SOSTENIBILIDAD URBANA}

Aunque no existe una única definición de aquello que entendemos por políticas urbanas, expresión que necesariamente debemos utilizar en plural, dados los distintos niveles de gobierno que implican, «podemos convenir que son medidas y acciones, gestionadas y desarrolladas por un gobierno local, cuyo objetivo es incidir en aquello que en cada momento se entiende como problemático o necesario en la ciudad real» (Bellet, 2020: 3). Políticas que se han ido configurando alrededor de los ejes de desarrollo económico, ordenación urbanística y servicios a las personas, añadiendo una dimensión transversal de sostenibilidad ambiental que debe conectarse con las dinámicas de inclusión social. Políticas en todo caso horizontales, intersectoriales, que acumulan una densa interrelación de aspectos económicos, culturales, espaciales, ambientales, sociales, que determinan el día a día de los asuntos que afectan directamente a la calidad de vida de los ciudadanos.

Los gobiernos locales se ven abocados a tener que tomar decisiones a modo de agentes dinamizadores de su territorio, modificando sus formas clásicas de hacer, impulsados tanto por exigencias de nuevas demandas, como por las exigencias que la globalización ha impuesto. La salida de la crisis económica desencadenada a partir del año 2008 evidenció especialmente la dificultad y las limitaciones que existen por parte de los gobiernos locales para adaptarse a estas demandas y exigencias ${ }^{4}$, obligándolos a desplegar estrategias de desarrollo con un perfil competitivo, a la promoción de las ciudades en detrimento de la ruralidad, en un contexto de «financiarización» de las intervenciones urbanas, de un urbanismo a la carta que no termina de desaparecer en nuestras grandes y medias ciudades, pese a presentarse, una vez y otra vez, como un modelo agotado que multiplica la lógica de «la ciudad de fragmentos» (Bellet, 2020: 30). Ramió se ha referido a la confusión que suele existir entre «institución» y «organización» en muchos responsables políticos y administrativos en España, que descubrieron, de la mano de los postulados de la Nueva Gestión Pública, que las Administraciones tenían básicamente problemas organizativos para prestar servicios con suficientes niveles de eficacia y eficiencia, y esto era un problema, ciertamente, de déficit de buena gestión, de estructuras organizativas arcaicas. El dominio del pensamiento «gerencial» hizo percibir que los únicos problemas de las instituciones administrativas eran solo de carácter organizativo y que mediante estos nue-

4 La configuración de la estructura económica de las ciudades españolas cuando empezó la crisis del 2008 era el resultado, en buena medida, de cómo estas fueron capaces de sobreponerse a la crisis industrial de los 80 y sus estrategias de inserción en la globalización. La crisis económica de 2008 vino a empeorar y profundizar también las desigualdades regionales existentes y más dificultades en aquellas ciudades que ya partían de una peor posición como consecuencia de la crisis industrial de los ochenta o con la reestructuración económica que se inicia en los 90. En general, es de destacar el menor nivel de desempleo en aquellas ciudades que no pudieron o no quisieron desarrollar una estrategia intensiva basada en el sector de la construcción, que acabaron sufriendo menos el impacto del desempleo. Aunque muchas de ellas aún afrontan las dificultades de reestructuración de los sectores primario e industrial, sus problemas de desempleo están más ligados a estos procesos anteriores a 2008, aunque obviamente también les haya acabado afectando. Véase así en SUBIRATS et al. (2015: 345-373), para quienes la capacidad de los gobiernos locales para generar «visiones más o menos hegemónicas respecto al rumbo que debe tomar la ciudad», se mantuvieron potentes allá donde ya se habían adquirido: «Un rasgo común, de índole analítico, para el conjunto de las ciudades, a saber, el impacto de la crisis y las estrategias relacionadas con ello dependen, en buena parte, de las dinámicas previas. Las condiciones y decisiones adoptadas previamente condiciona la intensidad y formas que adopta la crisis, y con ello, las estrategias que los actores configuran». 
vos instrumentos no solo mejoraría la gestión pública sino que permitiría también reformar las instituciones, y no ha sido así ${ }^{5}$. Ciertamente, es en el desarrollo de las nuevas políticas urbanas que se van perfilando desde la Unión Europea que encontramos más innovaciones desde el punto de vista de la gestión pública en las últimas décadas (Iglesias et al., 2011), pero de manera improvisada y fruto de la necesidad, en una aproximación escasamente institucional, porque no existe un marco claro predispuesto para ello.

Nuevos enfoques metodológicos predispuestos para el desarrollo de las políticas urbanas se van estableciendo en el nivel internacional y, sobre todo, en el comunitario europeo, que determinan que tengamos que familiarizarnos -irremediablemente cuando se trate de la gestión de proyectos urbanos que cuenten con financiación europea-, con nuevos valores culturales, reglas y principios. La experiencia generada en torno al cada vez más consolidado modelo de desarrollo urbano europeo que las entidades locales, los municipios en particular, han ido adquiriendo en el transcurso de la ejecución de los fondos comunitarios a los que concurren, va conformando un cuerpo de conocimiento sustantivo, una metodología de acción pública común ${ }^{6}$, y buenas prácticas en materia urbana (De Gregorio, 2020; De Gregorio, 2014; Huete et al., 2016). Aunque la Unión Europea no tiene competencias en materia de desarrollo urbano, desde la década de los ochenta es muy significativa la creciente producción de documentos de orientación política que han favorecido la visibilidad del fenómeno urbano en la política comunitaria, y que ha supuesto sin ningún género de dudas un marco de «armonización» informal a partir del cual establecer un esquema común para desarrollar nuevas políticas urbanas en la práctica. Gracias a un proceso intergubernamental continuado de más de tres décadas de duración se ha establecido así un consenso europeo explícito sobre los principios del desarrollo urbano sostenible que ha facilitado la creación de una cultura de acción local colaborativa sobre asuntos urbanos.

Algunos de los valores que forman parte de este cuerpo de conocimiento procedente del modelo urbano europeo los hemos incorporado a nuestro ordenamiento jurídico. Es el caso del principio de desarrollo urbanístico y territorial sostenible ${ }^{7}$; o el principio de integración de la sostenibilidad del medio urbano en todo tipo de políticas públicas ${ }^{8}$. Por esta vía, la dimensión sustantiva de la sostenibilidad urbana, relacionada con sus objetivos, dispone ya de un marco jurídico. No así la forma en que se aborda la gestión urbana, tanto en el seno de la administración local como en relación a actores ajenos a ella; es lo que denominaríamos la dimensión procedimental o metodológica de la sostenibilidad urbana. Una metodología de gestión que las entidades locales deben desarrollar cuando desarrollen proyectos urbanos que cuenten con financiación europea, y que está necesitada de un marco jurídico-institucional y organizativo que la consolide, y dé soporte a una renovada acción local.

Nuevos enfoques y reglas procedimentales de gestión, basadas en la interacción en red de actores diversos, públicos y privados, que se reconocen interdependientes y que actúan conjuntamente para lograr objetivos comunes, son ya una realidad a la que se enfrentan las entidades locales en el transcurso de la ejecución de los fondos comunitarios que financian proyectos de desarrollo urbano, o para poder acceder a otras fuentes de financiación europea, que cobran especial trascendencia en el actual escenario de crisis

5 Véase el análisis de la ciencia política de los modelos o patrones conceptuales de la Administración pública española desde finales del siglo XIX, clientelar, burocrática, gerencial y de gobernanza, en RAMIÓ, 2017, 128 y ss.

6 Fruto de las experiencias adquiridas con la gestión de los proyectos piloto URBAN, dos rondas de iniciativas comunitarias URBAN del Fondo de Desarrollo Regional Europeo (FEDER) -URBAN I (1994-99) y URBAN II (2000-06)-, el mainstreaming, de desarrollo urbano a través de los marcos estratégicos nacionales de referencia y los programas operativos regionales del periodo $2007-2013$ (que España incorpora a través del "Eje 5: Desarrollo Local y Urbano" con la iniciativa nacional URBANA), cuyo enfoque se mantiene en el actual periodo 2014-2020 a través del programa previsto en el artículo 7 del Reglamento 1301/2013 del Parlamento Europeo y del Consejo de 17 de diciembre de 2013 sobre el Fondo Europeo de Desarrollo Regional, al que España da cumplimiento con la programación del "Eje 12: Desarrollo Urbano Integrado y Sostenible" del Programa Operativo de Crecimiento Sostenible.

Art. 3 TRLSRU, «Las políticas públicas relativas a la regulación, ordenación, ocupación, transformación y uso del suelo tienen como fin común la utilización de este recurso conforme al interés general y según el principio de desarrollo sostenible, sin perjuicio de los fines específicos que les atribuyan las Leyes» (apartado 1). «En virtud del principio de desarrollo sostenible, las políticas a que se refiere el apartado anterior deben propiciar el uso racional de los recursos naturales armonizando los requerimientos de la economía, el empleo, la cohesión social, la igualdad de trato y de oportunidades, la salud y la seguridad de las personas y la protección del medio ambiente, contribuyendo en particular a: a) La eficacia de las medidas de conservación y mejora de la naturaleza, la flora y la fauna y de la protección del patrimonio cultural y del paisaje. b) La protección, adecuada a su carácter, del medio rural y la preservación de los valores del suelo innecesario o inidóneo para atender las necesidades de transformación urbanística. c) La prevención adecuada de riesgos y peligros para la seguridad y la salud públicas y la eliminación efectiva de las perturbaciones de ambas. d) La prevención y minimización, en la mayor medida posible, de la contaminación del aire, el agua, el suelo y el subsuelo» (apartado 2).

8 Art. 3.3 TRLSRU, «Los poderes públicos formularán y desarrollarán, en el medio urbano, las políticas de su respectiva competencia, de acuerdo con los principios de competitividad y sostenibilidad económica, social y medioambiental, cohesión territorial, eficiencia energética y complejidad funcional, procurando que, esté suficientemente dotado, y que el suelo se ocupe de manera eficiente, combinando los usos de forma funcional. En particular (...)». 
económica. Lo vemos con lo que sucede, por ejemplo, con el Pacto Europeo por el Clima, una plataforma de cooperación entre los entes locales y regionales y las instituciones europeas para dotar a la UE de una economía sostenible. La realización de este objetivo exigirá transformar los retos climáticos y medioambientales en oportunidades de financiación en todos los ámbitos, pero también para hacer frente a la crisis económica provocada por la pandemia. Ambos objetivos se van a abordar ahora de manera simultánea en este Pacto. Cobra trascendencia porque en la propuesta de la Comisión Europea se destaca que de lo que se trata es de hacer que «los ciudadanos y sus comunidades participen en la concepción de acciones en favor del clima y el medio ambiente mediante medidas concretas sobre el terreno, el fomento de un diálogo abierto con todos los agentes, la creación de sinergias, y el refuerzo de las capacidades», otorgando a los entes locales un papel «proactivo», reconociéndoles «como responsables fundamentales de la toma de decisiones a la hora de responder en primera línea a las necesidades y retos locales, incluso en períodos de emergencia mundial», señalando que «las comunidades locales y sus ciudadanos deben volver a asumir su papel, que se ha visto distorsionado por la globalización y la industrialización, y convertirse en socios clave para concebir acciones por el clima y configurar su entorno». Los entes locales y regionales tendrán acceso directo a los fondos europeos (procedentes tanto del presupuesto europeo como de otras instituciones financieras europeas, por ejemplo, el BEI). En este contexto, el Pacto por el Clima se va a convertir en una plataforma destinada a incrementar las posibilidades de que los entes locales obtengan financiación directa para sus acciones sostenibles, por tanto, para desarrollar también políticas urbanas conforme al modelo de desarrollo sostenible europeo. Las reglas procedimentales para su gestión se asientan en los mismos enfoques metodológicos.

En un contexto caracterizado por la complejidad, en el que hay que gestionar partiendo de las mutuas interdependencias entre ámbitos temáticos y competenciales, el carácter eminentemente horizontal de las políticas urbanas requiere un entramado colaborativo y de cooperación institucionalizado. La dimensión procedimental del modelo de desarrollo urbano europeo hace precisamente referencia al proceso de integración de los diferentes actores públicos y privados que se ven implicados porque puedan estar afectados por los mismos problemas o por sus posibles soluciones.

Reformar la legislación básica del régimen local en conexión con la del régimen del suelo ofrecería la oportunidad para conjugar en coherencia no solo toda una serie de ámbitos materiales con presencia de intereses locales ahora desatendidos, sino para articular y fortalecer las capacidades institucionales de la Administración local tomando en consideración una serie de dinámicas que confluyen en la acción local en las ciudades, y que desarticuladas como están debilitan la gestión pública. Y habrá que superar el limitado marco jurídico que en la actualidad ofrece el Real Decreto legislativo $7 / 2015$, de 30 de octubre, por el que se aprueba el texto refundido de la Ley de Suelo y Rehabilitación Urbana, cuya comprensión sectorial de la sostenibilidad y la desatención a las lógicas de fragmentación y complejidad que la cuestión urbana tiene -aproximación imprescindible para adaptarse a las especificidades del fenómeno urbano- no lo facilita.

No obstante, a la hora de reformar no todo consiste en efectuar cambios normativos. Reformas meramente organizativas, procedimentales, competenciales, serían totalmente inútiles si no recuperan al gobierno y administración local como las instituciones de proximidad que son para la gestión de los asuntos que afectan a la colectividad, en esa transformación de la lógica jurídico-administrativa que antes referíamos para la gestión pública de las políticas urbanas. A ello apuntaba la Estrategia Española de Sostenibilidad Urbana y Local cuando hacía referencia a la necesidad de una nueva «institucionalidad, capaz de gobernar la complejidad, evitando la gestión tradicional basada en la fragmentación y el solapamiento institucional» ${ }^{9}$. Más allá, no se trataría únicamente de la eficacia o la eficiencia de las políticas públicas que se pongan en marcha, sino sobre todo de mayor calidad de la democracia local, la legitimidad de los actores que toman esas decisiones y la forma en la que lo hacen (Subirats et al. 2015: 345).

Los cambios culturales que van de la mano de las dimensiones sustantiva y procedimental de la sostenibilidad en el modelo europeo, y el proceso de aprendizaje que las entidades locales se ven en la tesitura de seguir en su gestión, requieren de un continuado e intenso impulso político en la misma dirección; para combatir las inercias o la tendencia a mantener las lógicas con las que siempre se vienen haciendo las cosas en el pasado ${ }^{10}$, que no suelen desaparecer, pero se transforman.

9 Lo hace a propósito de las relaciones rural-urbano, «que carecen de una institucionalidad compartida que les permita reconocer la multifuncionalidad de las actividades que se desarrollan en ambos espacios, la mixticidad de usos o la relevancia de los flujos de interacción existentes» (Directriz 5.6).

10 Como señala, en un contexto más general, combatir las inercias administrativas, la manera en que «siempre» se han venido haciendo las cosas, requiere tomar en consideración que, «en España se han producido importantes transformaciones legislativas y 
Las nuevas reglas, enfoques, valores que en este proceso de aprendizaje «forzado» se están proyectando sobre la gestión local del desarrollo urbano sostenible vendrían a determinar transformaciones en las que la lógica jurídico-administrativa que pone el foco de la acción pública en las estructuras, competencias y procedimientos administrativos, se traslada a la lógica de las políticas públicas; esto es, a los problemas y a las posibilidades para resolverlos. Así, la armonización europea de las políticas urbanas potencia los enfoques integrados y participativos, caracterizados por una aproximación estratégica para el desarrollo de los territorios urbanizados, que coordine a los diferentes actores en presencia en función de sus respectivas funciones, herramientas y escalas de intervención, asegurando que los ciudadanos participen activamente, con integración intersectorial, que impulse a actuar a través de ámbitos de políticas públicas (policy-areas), con la integración de múltiples fuentes de financiación, promoviendo lógicas orientadas a resultados (resultoriented) y estableciendo marcos para el seguimiento y la evaluación ${ }^{11}$. Y donde debe importar menos la concreta intervención o proyecto urbano a realizar -y la ayuda económica que la acompaña-, que la valoración a medio y largo plazo de los efectos en el territorio y en la colectividad, de la actuación llevada a cabo.

Esto no es algo que se pueda hacer exclusivamente con las capacidades institucionales que hoy por hoy tienen, en cada nivel competencial, las administraciones concernidas ${ }^{12}$. Por eso está resultando tan difícil a los gobiernos locales los cambios de lógica, y emprender un camino decidido que transforme la acción pública local. La ciencia urbana viene poniendo de manifiesto que "falta un diagnóstico que permita entender por qué las ciudades no han avanzado en sostenibilidad, y en esta reflexión se verá cómo emergen problemas que enfrentan a diario las ciudades, sobre todo medias y pequeñas, como una deficiente capacitación técnica de los empleados públicos orientada al nuevo escenario urbano, falta de información e indicadores, falta de herramientas de diagnóstico, seguimiento, evaluación y aprendizaje, aproximación estrictamente sectorial y cortoplacista en el ejercicio de las competencias administrativas que tienen dimensión urbana, en detrimento de una visión estratégica a corto, medio y largo plazo (De Gregorio et al., 2020).

Las experiencias de gestión urbana con financiación comunitaria evidencian también que los cambios no solo precisan que las administraciones puedan establecer el marco en el que situar actuaciones pensadas y gestionadas desde la proximidad. Tiene que hacerse contemplando la multiplicidad de actores implicados, para lo que la propia sociedad y sus estructuras tienen que asumir la parte de responsabilidad que les corresponden, y en la que las administraciones no pueden sustituirlas.

Como decimos, todo un nuevo cambio de lógicas de acción local se asocia a las políticas urbanas, acompañado de un arsenal metodológico predispuesto para la gestión pública, desde la construcción de consensos que propicien la convergencia y la colaboración, no siendo suficientes los instrumentos convencionales para la interacción entre gobierno local, sociedad civil y organizaciones privadas.

Y no se trataría de la utilización de las fórmulas de colaboración público-privada que llevan décadas dominando el panorama de la gestión indirecta de servicios públicos, o para el establecimiento de compromisos entre las administraciones públicas y el tejido empresarial con conciertos de distinto tipo, o para realizar infraestructuras públicas, o para externalizar servicios ${ }^{13}$. Se trataría de profundizar y avanzar en sistemas

de ordenación política del territorio (...). Sin embargo, la evolución de la cultura preexistente, conceptuada como centralista, pervive en muchas actitudes y en algunas instituciones. Esto muestra un cierto fracaso de los que han puesto el énfasis exclusivamente en los aspectos normativos, olvidándose de los valores culturales. Éstos se han ido construyendo desde principios del siglo XIX (...). No debe extrañar, por tanto, que lo que se ha entendido como progreso o como solución a los problemas de unidad durante tanto tiempo cueste cambiarlo en solo dos décadas» (ARENILLA (2012: 99).

11 Véase el Informe BARCA, "An Agenda for a reformed cohesion policy" (2009). Para contribuir al debate sobre el futuro de la política de cohesión, la Comisaria Danuta Hübner pidió a Fabrizio Barca (Director General del Ministerio italiano de Economía y Finanzas) que elaborase un informe independiente en el que se evaluase la eficacia de la política de cohesión hasta la fecha y se presentasen una serie de propuestas sobre cómo reformar dicha política para el período posterior a 2013. El informe trata de la justificación económica y la motivación de una política de desarrollo basada en criterios geográficos en la UE y evalúa la política de cohesión de la UE. Además, indica algunas prioridades esenciales en las que centrar tal política. Por último, presenta recomendaciones sobre pilares esenciales de la gobernanza de la política de cohesión que convendría reformar. Se encuentra accesible en: https://ec.europa.eu/regional_policy/ archive/policy/future/pdf/report_barca_v0306.pdf.

12 En el mejor de los casos, como ha estudiado DE GREGORIO (2017: 402-414), «las estrategias que se han puesto en marcha han dado lugar a una mejora del área en la que han operado, pero tendrán dificultades para que esos resultados sean duraderos, ya que no contribuyen suficientemente al reforzamiento de la capacidad local ni a mejorar el grado de sostenibilidad y resiliencia del área desde una visión holística e integrada de la entera ciudad».

13 En España las lógicas de colaboración público privada nunca han sido pacíficas sino más bien conflictivas. Se ha ido generando una desconfianza mutua entre sector público y sector privado. Sirvan como indicadores de estos desencuentros la legislación en materia de contratos del sector público, basada en la desconfianza, o las recientes estrategias políticas de republificación o remunicipalización de determinados servicios públicos. Véase sobre esta desconfianza e interacciones entre ambos sectores RAMIÓ (2020) 
de colaboración más sofisticados, como los partenariados público-privados, una herramienta que facilita la implicación de distintos actores interdependientes, para la realización de los objetivos en que todos están implicados, desde la interacción, compartiendo responsabilidades. Partenariados como los que la metodología de ejecución de la estrategia comunitaria LEADER ha ido introduciendo para la gestión local de actuaciones en el medio rural. Una metodología de gestión colaborativa ha pasado a incorporarse al llamado Community Led Local Development (CLLD), como herramienta específica para el desarrollo local participativo en las zonas urbanas. Es una forma de aproximación a los problemas urbanos de abajo arriba (button-up), que trata de alentar la cooperación entre lo público, lo privado y los sectores de la sociedad civil, y así lograr el despliegue de una estrategia de desarrollo integrado y sostenible a través de un partenariado que gestionará fondos propios, públicos y comunitarios ( $5 \%$ de los FEDER en el caso del eje urbano), en base a objetivosresultados y no tanto para la compensación o paliación de problemas. La aplicación de esta herramienta es determinante, puesto que es "obligatoria» para todas aquellas administraciones y entidades que aspiren a obtener Fondos Estructurales y de Inversión Europeos (Fondos EIE) y más concretamente los FEDER, FSE, COHESIÓN, FEADER y FEMP, que les permitan financiar diversos proyectos urbanos (bajo el denominado Eje Urbano 12) y que por tanto se encuadren en los programas operativos del Estado 2014-2020.

Por lo dicho hasta el momento, el reposicionamiento que las Administraciones públicas, en general, están llamadas a emprender en escenarios tan complejos como los que tienen que ver con el desarrollo sostenible determinan estar llamadas a ejercer sus competencias en un nuevo papel institucional; un papel para el que se ha utilizado por la ciencia política el término de «metagobernador» (Ramió 2018: 126). Más que desarrollar sus competencias en términos de relaciones jurídico-públicas clásicas -interadministrativas y con «administrados»-, deben hacerlo de forma colaborativa con múltiples actores, que han de corresponsabilizarse también en la búsqueda y desarrollo de soluciones para los retos de las sociedades actuales. Sociedades complejas e interdependientes ${ }^{14}$ donde las ciudades han emergido como lugares de nueva centralidad política, son también un «actor», un actor colectivo, pero no son sujetos jurídicos. La acción pública local tiene que desenvolverse, en cualquier caso, con un renovado modelo de gestión.

\section{HACIA LA SUSTANTIVACIÓN JURÍDICA DE UN NUEVO MODELO DE GESTIÓN LOCAL}

En los escenarios de cambios con lo que arrancábamos este trabajo, lo local, junto con la participación social, se encuentra en el centro de todos los debates encaminados a prestar beneficios a la ciudadanía. Se constata la creciente relevancia de la esfera local como espacio de producción de políticas públicas y sus consecuentes procesos de ampliación y profundización del poder del «gobierno local tradicional» (Blanco, 2012). Y si bien es cierto que el despliegue de las políticas públicas no depende solo de decisiones tomadas en la esfera local, si van a requerir de ejecución a nivel local; más si de políticas de desarrollo sostenible se trata, un concreto problema en un entorno urbano puede tener síntomas muy locales pero requerir una solución a mayor escala. Las políticas urbanas deben entenderse y gestionarse en un contexto multiescalar, desde el punto de vista espacial y organizativo. Por ello se parte de metodologías que tienen enfoques funcionales y flexibles, con independencia de los ámbitos competenciales de los distintos niveles de gobierno territoriales que resulten implicados.

\subsection{La escala espacial: Áreas urbanas funcionales}

Los principios, reglas y metodologías de gestión del modelo de desarrollo urbano europeo precisan un contexto multiescalar. Es responsabilidad de las autoridades urbanas definir la escala territorial apropiada donde desplegar las políticas urbanas. Luego nos referiremos a las autoridades urbanas, ahora se trata de identificar el territorio donde deba desarrollarse la acción local.

Dados los retos y objetivos de la sostenibilidad, parece lógico que la escala debe extenderse al entero territorio donde se desenvuelven las distintas dinámicas y flujos urbanos. Recordemos que en el desarrollo metodológico de estas políticas ya no se pone el foco aisladamente en actuaciones puntuales en zonas urbanas homogéneas, concretas y limitadas (enfoque area-based), sino que la cofinanciación europea de

14 Las limitaciones del Estado del bienestar para dar respuestas a una sociedad compleja e interdependiente, junto a las presiones de la internacionalización de la economía y la necesidad de replantear las relaciones entre los ámbitos público y privado, se pretenden superar con la construcción del llamado Estado relacional. Véase al respecto YSA (2004). 
actuaciones urbanas lo va a ser en función de las especificidades que presente cada lugar. Esto es, precisan de la previa elaboración de una estrategia de lugar que tome en consideración la complejidad territorial que tiene el fenómeno urbano, la ciudad real (enfoque place-based). Aunque la intervención concreta se desarrolle, en última instancia, en un barrio, un distrito urbano, o en cualquiera otra área homogénea, concreta y limitada dentro de la ciudad real.

No existe una definición previa de qué territorios deban ser considerados como un área espacial idónea para desplegar políticas urbanas de desarrollo sostenible, eso que hemos llamado «estrategia de lugar». El art. 7 del Reglamento 1301/2013 del Parlamento Europeo y del Consejo, de 17 de diciembre de 2013, sobre el Fondo Europeo de Desarrollo Regional (FEDER) deja no obstante establecidas algunas pautas para su comprensión: «El FEDER apoyará, mediante programas operativos, el desarrollo urbano sostenible a través de estrategias que establezcan medidas integradas para hacer frente a los retos económicos, ambientales, climáticos, demográficos y sociales que afectan a las zonas urbanas, teniendo en cuenta al mismo tiempo la necesidad de promover los vínculos entre el ámbito urbano y el rural».

Como decimos, serán las autoridades urbanas las que deban definir la escala territorial apropiada para cumplir con los requisitos del artículo 7 del Reglamento FEDER, que establece también que los principios para seleccionar las zonas urbanas en las que deban aplicarse las acciones integradas para un desarrollo urbano sostenible y los importes indicativos previstos para dichas acciones deben fijarse en los Acuerdos de Asociación de los Estados Miembros con la Comisión, con un mínimo de un $5 \%$ de recursos del FEDER asignados para dicho fin a escala nacional. Al respecto, el Acuerdo de Asociación de España 2014-2020, aprobado por la Comisión Europea el 30 de octubre de 2014, no clarifica mucho más, limitándose a establecer que «a las nuevas propuestas para el desarrollo urbano sostenible se les exigirá estar respaldadas por una estrategia bien definida y a largo plazo que sirva de marco de referencia territorial y sectorial para todas aquellas operaciones o intervenciones a implementar, que deberán contribuir a dicha estrategia de manera coherente».

En cualquier caso, lo que queda claro es que el territorio de la estrategia de lugar, es el territorio donde deberán concretarse después las unidades de actuación para las que se solicite la cofinanciación. El espacio de «las operaciones o intervenciones a implementar» -el espacio de los proyectos urbanos, de las actuaciones de transformación urbanística-, no necesariamente será el mismo que el de la estrategia. Su delimitación compete, insistimos, a la autoridad urbana. Que son espacios distintos queda claro en el Anexo I de la Orden HAP/2427/2015, de 13 de noviembre, que dice expresamente que el área funcional será «el soporte efectivo para una Estrategia DUSI a largo plazo, y no simplemente el área donde se ejecutarán operaciones puntuales de mejora urbana (...)». La escala del área urbana elegida para ejecutar las operaciones, los proyectos urbanos, se condiciona además a tener la suficiente masa crítica como para implementar al menos dos de los objetivos temáticos del FEDER -objetivos siempre transversales-, lo que deberá explicarse de forma razonada y pormenorizada.

En virtud de esta Orden HAP/2427/2015, de 13 de noviembre, se aprueban las bases y la primera convocatoria para la selección de estrategias de desarrollo urbano sostenible e integrado (EDUSI) que serán cofinanciadas mediante el programa operativo FEDER de crecimiento sostenible 2014-2020 ${ }^{15}$ donde se encuentra una clarificación del ámbito espacial de este instrumento financiero -EDUSI- o lo que es lo mismo, el ámbito de la estrategia de lugar. De conformidad con su Disposición General Sexta: «Las EDUSI deberán desarrollarse en las ciudades o áreas funcionales urbanas según se definen en el Anexo I de esta convocatoria (...). Las áreas funcionales que se constituyan deberán estar formadas por municipios pertenecientes a la misma comunidad autónoma».

15 Esta Orden tenía un doble objetivo: Por un lado, articular la presentación y establecer los criterios para el análisis y selección de Estrategias de Desarrollo Urbano Sostenible Integrado susceptibles de recibir ayudas FEDER en $2014-2020$ con cargo al POCS. Estas Estrategias debían contemplar los cinco retos siguientes: económicos, ambientales, climáticos, demográficos y sociales, según lo dispuesto en el artículo 7.1 del Reglamento FEDER, para favorecer el desarrollo urbano sostenible, de acuerdo a los principios y orientaciones estratégicas de los Fondos EIE. Por otro lado, las Estrategias constituirán el marco para la posterior selección, por parte de las Entidades beneficiarias, de las operaciones a desarrollar en la ciudad o área funcional definida en cada caso, las cuales serán cofinanciadas mediante las ayudas concedidas a través de la presente convocatoria. La primera convocatoria se dotó con un $70 \%$, aproximadamente, del total de la ayuda FEDER destinada al eje urbano dentro del POCS: 730,9 millones de euros de ayuda. Mediante la Orden HAP/1610/2016, de 6 de octubre, se aprueba la segunda convocatoria, con un importe total de 281,84 millones de euros. La Orden HAP/888/2017, de 19 de septiembre, por la que se modifica la Orden HAP/2427/2015, de 13 de noviembre, por la que se aprueban las bases y la primera convocatoria, y por la que se aprueba la tercera convocatoria para la selección de las citadas estrategias. El importe total de esta tercera convocatoria fue de 353,40 millones de euros. 
REALA. Nueva Época - N.o 14, octubre 2020 - ISSN: 1989-8975 - DOI: https://doi.org/10.24965/reala.i14.10808 - [Págs. 49-68]

Repensar la acción pública local desde nuevos modelos de gestión administrativa

María Rosario Alonso Ibáñez

El Anexo I establece la tipología de áreas funcionales urbanas, y en función de cada una, va concretando el territorio de la estrategia:

En el caso de que se trate de "Áreas constituidas por un único municipio con una población mayor de 20.000 habitantes», de conformidad con lo establecido en el citado Anexo, las estrategias podrán referirse a la totalidad del término municipal, o limitarse a áreas urbanas inframunicipales de diferente tipología morfológica y funcional (centros históricos, barrios desfavorecidos o áreas suburbanas con problemáticas específicas y retos singulares).

Si se trata de «Agrupaciones de municipios con una población de cada uno de ellos superior a 20.000 habitantes», en este caso podrán presentar conjuntamente una estrategia a escala supramunicipal de manera conforme a la definición del área funcional urbana de dicha estrategia. Las estrategias deberán justificar de forma coherente y razonada la existencia de problemas comunes, la complementariedad de funciones urbanas, así como la explicación de que abordarlos de forma conjunta es la forma óptima de conseguir las soluciones a dichos problemas. Deberán asimismo explicar de qué manera se intensificarán las relaciones entre los municipios para aprovechar sinergias y complementariedades.

Cuando se trate de "Áreas urbanas formadas por un municipio o conurbación de más de 20.000 habitantes y municipios periféricos de menos de 20.000 habitantes», los municipios o conurbaciones de más de 20.000 habitantes que constituyan el centro de áreas urbanas de otros municipios de menos de 20.000 habitantes, podrán presentar de forma conjunta estrategias para ese territorio, constituido por el territorio del municipio central o conurbación central (mayor de 20.000 habitantes), y otro u otros municipios (menores de 20.000 habitantes) cuyos términos municipales sean limitrofes al del primero. Las estrategias deberán justificar de forma coherente y razonada la existencia de problemas comunes que afectan a la aglomeración urbana en su conjunto, la promoción de los vínculos entre el ámbito urbano y el rural, así como la explicación de que la escala urbana supramunicipal es la óptima para abordar las soluciones a dichos problemas.

Cuando se trate de «Conurbaciones de población superior a 20.000 habitantes, constituidas por agrupaciones de municipios de menos de 20.000 habitantes que presenten una continuidad urbana física, de forma que constituyan morfológicamente un único núcleo urbano», en este caso, el territorio de la estrategia será el del área funcional urbana. En esta tipología se engloban las «áreas policéntricas», caracterizadas por la existencia de varios centros que coexisten en un territorio con relaciones tanto de competencia como de complementariedad. Son áreas urbanas funcionales que no tienen una dependencia marcada de un núcleo central y comparten problemas comunes de diverso orden. Estas estrategias deberán justificar de forma coherente y razonada la existencia de problemas comunes, demostrar la continuidad física urbana, así como la explicación de que la escala urbana supramunicipal es la óptima para abordar las soluciones a dichos problemas.

Podríamos preguntarnos qué papel desempeña el «barrio», entendido como fragmento urbano en esta realidad espacial que venimos refiriendo. La desagregación de los tejidos urbanos (llámense comunidades vecinales, barrios, o distritos) es bien conocida y utilizada sistemáticamente por la ciencia urbana como referencia social y espacio de identidad, incluso el legislador de la reforma local del año 2003 la acoge a los efectos de facilitar la participación ciudadana. Sin embargo, el renacimiento del barrio en la planificación urbanística como instrumento específico de ordenación, diseño y gestión urbanos es más reciente. En cualesquiera proyectos de ciudad, el barrio que se había consolidado en la técnica urbanística española con el Reglamento de Planeamiento de 1976 como referencia en los planes parciales, ha reaparecido como elemento articulador de los componentes de la estructura urbana tras la última crisis inmobiliaria y la vuelta al urbanismo de la rehabilitación y renovación urbanas en los suelos urbanos. Algunas Comunidades Autónomas han incorporado en su normativa urbanística nuevas figuras destinadas a la ordenación del suelo urbano distintas de la definición de ámbitos puntuales de intervención, cuyo objetivo es ofrecer una lectura articulada del conjunto de los tejidos urbanos existentes. Se cuenta así con ámbitos que facilitan las estrategias de intervención urbanística capaces de diferenciar, seleccionar, priorizar y definir las acciones de mejora en clave de sostenibilidad. Desde esta consideración, el concepto de barrio es en la actualidad útil tanto en el diagnóstico como en la priorización de ámbitos de intervención, pero también en el despliegue de nuevas técnicas de ordenación que hagan posible la adaptación a los objetivos de sostenibilidad.

En cualquiera de las tipologías que se acaban de referir, el territorio donde desplegar las políticas urbanas, la acción local, y desarrollarse la gestión pública, va a ser un área urbana funcional; un territorio que puede no ser coincidente con el territorio del ente local. 


\subsection{La escala organizativa: Autoridades urbanas}

Es insistente la apelación que desde la instancia comunitaria se hace al papel que las entidades locales han de desempeñar en la ejecución de las políticas europeas en el ámbito interno de cada Estado miembro. Una insistencia que va más allá de conminar a los Estados a que la integren en la fase estatal de aplicación del derecho europeo, atribuyendo directamente funciones gestoras a las entidades locales de cada uno de los Estados, como sucede con la llamada «autoridad urbana».

En una progresiva institucionalización de la acción pública local para el desarrollo urbano sostenible no será suficiente con nuevas divisiones administrativas del territorio sino existe una voluntad política expresa de ocupar el nuevo espacio ${ }^{16}$, algo a lo que se encamina el Reglamento (UE) 1301/2013, de 17 de diciembre, ya citado, otorgando sustantividad jurídica a lo que llama autoridad urbana, condición que asigna a quien va a asumir la responsabilidad de la aplicación de "estrategias integradas de desarrollo urbano sostenibles», y que identifica bajo la referencia a «las ciudades, los organismos subregionales o locales» ${ }^{17}$.

Ya hemos señalado que las ciudades no son hoy por hoy, sujetos jurídicos, por mucho que sean «un imprescindible actor global que requerirá de una específica ordenación» (FONT, 2020). Identificar quién sea la autoridad urbana, que se encuentra en línea de continuidad con el concepto de área urbana funcional, requiere partir de los sujetos que tengan la condición de ente territorial local.

El concepto no se asocia, en exclusividad, con el municipio, sino que puede conllevar el ensamblaje de nuevas formas de asociación institucional de todos aquellos entes o estructuras administrativas locales de una determinada área urbana. En este sentido, lo que debe existir es una coherencia entre la estrategia de lugar a que nos hemos referido antes, y la autoridad urbana que la sostiene e impulsa. A dichas autoridades urbanas el citado Reglamento FEDER les asigna una serie de funciones: por un lado, gestionar la EDUSI, «en colaboración con la autoridad de gestión » ${ }^{18}$; por otro, encargarse de las tareas relacionadas, por lo menos, con la selección de las operaciones, de conformidad con el artículo 123, apartado 6, del Reglamento (UE) $1303 / 2013$ o, según corresponda, de conformidad con el artículo 123, apartado 7, de dicho Reglamento ${ }^{19}$.

La autoridad urbana no será, en cualquier caso, quien ostente la condición de autoridad de gestión de la financiación comunitaria, que en todo caso es la Administración del Estado, que es quien tiene atribuidas las competencias para representar al Estado en sus relaciones con las instancias comunitarias. Tampoco lo podrán ser las Administraciones autonómicas, porque el texto del artículo 7.4 del Reglamento FEDER es claro, tienen que ser autoridades «subregionales» o «locales». Lo cual nos coloca, para el caso español, necesariamente, en el escalón de las entidades locales y en cómo se organice la cooperación intermunicipal en las áreas urbanas funcionales.

La Orden HAP se refiere a las autoridades urbanas como «entidades beneficiarias», y conforme a la Disposición Séptima.1: «A los efectos regulados por la presente orden, tendrán la condición de entidades beneficiarias los Ayuntamientos o las entidades supramunicipales, preexistentes o de nueva constitución, representantes de las áreas funcionales definidas en el anexo I que presenten Estrategias DUSI conforme a lo dispuesto en esta convocatoria y que resulten adjudicatarias».

El hecho de articularse las ayudas jurídicamente como subvenciones explica que la Orden HAP considere a las autoridades urbanas como entidades beneficiarias ${ }^{20}$. En este sentido, quien asume la totalidad de derechos y obligaciones inherentes a tal condición, necesariamente tiene que ser un ente, territorial o no,

16 Señala ARENILLA que, en la ordenación política del territorio, en general, «no solo se trata de dividir administrativamente el espacio del Estado con fines de eficacia, por ejemplo, sino que existe una voluntad expresa de ocupar todo el territorio, bien por medios propios o de forma indirecta a través de otras organizaciones territoriales» (2012: 91).

17 El artículo 7. 4 establece que «Al menos un $5 \%$ de los recursos del FEDER asignados a nivel nacional en virtud del objetivo "inversión en crecimiento y empleo" se asignarán a medidas integradas para el desarrollo urbano sostenible, en las que las ciudades, los organismos subregionales o locales responsables de la aplicación de estrategias urbanas sostenibles ("autoridades urbanas") serán los encargados de las tareas relacionadas, por lo menos, con la selección de las operaciones, de conformidad con el artículo 123, apartado 6, del Reglamento (UE) no1303/2013 o, según corresponda, de conformidad con el artículo 123, apartado 7, de dicho Reglamento. El importe indicativo destinado a los fines del apartado2 del presente artículo se establecerá en el o los correspondientes programas operativos».

18 De conformidad con el art.7.5 Reglamento 1301/2013, «La autoridad de gestión determinará, en colaboración con la autoridad urbana, el alcance de las tareas que deban emprender las autoridades urbanas relativas a la gestión de acciones integradas para el desarrollo urbano sostenible. La autoridad de gestión registrará formalmente su decisión por escrito. La autoridad de gestión podrá conservar el derecho a efectuar una comprobación final de la admisibilidad de las operaciones antes de la aprobación».

19 Artículo 7.4, transcrito en nota anterior.

20 La condición de entidades beneficiarias de las ayudas implica que estas asumen frente a los Organismos Intermedios de Gestión designados en esta orden, la totalidad de derechos y obligaciones inherentes a tal condición, en los términos de la Ley 38/2003, de 
personificado. La condición de autoridad urbana tiene por tanto que recaer en una entidad pública local: o municipios o entes supramunicipales ${ }^{21}$

El Anexo I de la Orden HAP/2427/2015 precisa que, en cualquier caso, «debe tratarse de autoridades apropiadas, con capacidad suficiente y demostrada para implementar y llevar a cabo las Estrategias (...). Deberán demostrar su capacidad en base a los criterios definidos en esta convocatoria, y según lo dispuesto en el Reglamento FEDER, el Acuerdo de Asociación y el Programa Operativo de Crecimiento Sostenible» 22. La "capacidad» que le es exigible a los entes locales se refiere en el Anexo II de la citada Orden HAP/2427/2015 -aunque más precisamente a lo que se está refiriendo no es a la capacidad sino a las posibilidades de organización administrativa interna del ente de gestión en cuestión-, señalando que «la Estrategia ha de incluir un resumen con la estructura de que se dispone o que se pretende crear para la implementación de la misma, ya sea encuadrándola dentro de la entidad beneficiaria o con personal externo creando una oficina de gestión que coordine su desarrollo y seguimiento. La entidad beneficiaria deberá disponer de un equipo técnico conocedor de la reglamentación y normativa tanto nacional como comunitaria sobre fondos europeos en lo relativo, especialmente, a: selección de operaciones (artículo 125.3 del Reglamento 1303/2013, de 17 de diciembre de 2013 disposiciones comunes de los Fondos Europeos), contratación pública, medio ambiente, igualdad de oportunidades y no discriminación, elegibilidad del gasto, información y publicidad y otras materias necesarias para cumplir correctamente con la legislación vigente, así como con conocimientos y experiencia en el campo del desarrollo urbano sostenible e integrado».

Como puede observarse, desde un enfoque funcional y flexible que respete el principio de subsidiariedad y las especificidades de los diferentes niveles territoriales., son posibles diferentes personificaciones públicas locales, dotadas de una organización administrativa ad hoc también plural, para gestionar estrategias DUSI adaptadas a una geografía funcional, las unidades territoriales urbanísticas.

En definitiva, la gestión local del desarrollo urbano sostenible precisa de enfoques flexibles. Pero no se asocia a una competencia administrativa, se presupone que la entidad de gestión correspondiente debe tenerlas ya: «debe tratarse de autoridades apropiadas, con capacidad suficiente y demostrada para implementar y llevar a cabo las Estrategias».

\section{FORTALECIMIENTO DE LAS CAPACIDADES INSTITUCIONALES}

Para la ciencia política, la capacidad institucional no se asocia a los títulos competenciales. Se asocia a la suficiencia de las Administraciones para responder a los retos clásicos que se le vienen planteando desde hace años. Esto es, una gestión basada en la eficacia, la eficiencia, el establecimiento de alianzas con otros actores, tanto en el seno de la administración como fuera de ella. Así, «podría afirmarse que la capacidad institucional hace referencia a la habilidad de las Administraciones para resolver problemas (eficacia), utilizando adecuadamente los recursos a su disposición (eficiencia) y estableciendo relaciones de colaboración con los actores del contexto en el que operan (relacional)» (Casado et al., 2018: 124).

Los nuevos enfoques metodológicos de la gestión del desarrollo urbano se vienen relacionando con las dos dimensiones que caracterizan a la denominada gobernanza urbana, «un paradigma tan seductor y benevolente como abstracto, ambiguo y confuso» (Ramió, 2017:137), que constituiría no obstante el escenario

17 de noviembre, General de Subvenciones, y del Real Decreto 887/2006, de 21 de julio, por el que se aprueba el Reglamento de la Ley General de Subvenciones (DG Séptima. 2).

21 Con imprecisión jurídica, el Anexo I de la Orden HAP/2427/2015 «recomienda» que lo que llama «unidad de gestión administrativa», esto es, la autoridad urbana en términos FEDER, «sea el propio Ayuntamiento del municipio» cuando el ámbito territorial de la Estrategia DUSI sean «áreas urbanas constituidas por un único municipio con una población mayor de 20.000 habitantes», ya se refieran a la totalidad del término municipal, o se limiten a áreas urbanas inframunicipales. Y si se trata de un área urbana policéntrica donde se articulan diversos núcleos urbanos -agrupaciones de municipios y conurbaciones con una determinada población-, la autoridad urbana podrá estar constituida por las diferentes «autoridades municipales» o por "entidades supramunicipales». Así: "Cuando el ámbito territorial sea el resultante de "agrupaciones de municipios con una población de cada uno de ellos superior a 20.000 habitantes", en este caso, recomienda que "los Ayuntamientos participantes deberán definir un único órgano de gestión administrativa", que podría ser uno de dichos Ayuntamientos o un órgano supramunicipal existente o de nueva constitución». Cuando se trate de "áreas funcionales constituidas por un municipio central o conurbación central (mayor de 20.000 habitantes) más otro u otros municipios (menores de 20.000 habitantes) cuyos términos municipales sean limítrofes al del primero», o de «conurbaciones de población superior a 20.000 habitantes, constituidas por agrupaciones de municipios de menos de 20.000 habitantes», en este caso, «los Ayuntamientos participantes deberán definir un único órgano de gestión administrativa para las Estrategias, que se recomienda sea el Ayuntamiento del municipio central de más de 20.000 habitantes, o un órgano supramunicipal existente o de nueva constitución».

22 Minuciosamente recogidos en el Anexo II de la Orden HAP/2427/2015, de 13 de noviembre. 
más probable de modelo de Administración pública del futuro, que «implica apostar conservadoramente por un modelo continuista de Administración, sin grandes cambios ni sobresaltos» ${ }^{23}$.

Siguiendo a Le Galès (1998), las dos dimensiones que caracterizan a este modelo, por un lado, «la capacidad para integrar organizaciones, actores, grupos sociales e intereses en la búsqueda de determinados objetivos (mecanismos de negociación en el desarrollo de las políticas públicas, buscar activamente el involucramiento de grupos de interés $u$ organizaciones de la sociedad civil junto a grupos de expertos, además de las propias instituciones de gobierno)». Por otro, «la capacidad de presentarse frente a otros actores externos y desarrollar y defender una estrategia unificada frente a los mercados, los niveles superiores del Estado u otras ciudades o regiones en competencia», estarían caracterizando también la dimensión procedimental o metodológica de la sostenibilidad urbana, conforme al modelo europeo, y de su mano, el proceso de aprendizaje que las entidades locales tienen que ir forzosamente adquiriendo, desarrollando su capacidad institucional.

Existe un reconocimiento explícito por parte de las instituciones europeas sobre el impacto que los fondos europeos producen en el desarrollo de la capacidad institucional de las entidades que los gestionan. Los recursos destinados específicamente a este aspecto en los Fondos Estructurales así lo evidencian ${ }^{24}$. Ahora bien, ¿hasta qué punto la gestión de las iniciativas y programas comunitarios ha producido cambios en la capacidad institucional de los municipios españoles, de manera que les permitan afrontar en mejores condiciones la ejecución de políticas urbanas? ${ }^{25}$ Se ha constatado que la política urbana europea tiene un impacto en la transformación de la capacidad institucional de los municipios que participan en ella, «y que además puede suponerse que no permanece solamente en las unidades administrativas directamente vinculadas a la gestión de los proyectos, sino que con ello se produciría un efecto de difusión de estos modelos de implementación en otras áreas de la administración, así como en otros ámbitos de política pública» (Casado et al., 2018: 140), produciéndose por tanto un crecimiento real en términos de capacidad institucional y no solamente una mera adaptación de las administraciones a los requerimientos establecidos por la reglamentación de la financiación comunitaria.

Por esta vía -y por lo dicho, no de manera generalizada, al ser fruto de aprendizajes adquiridos en la ejecución de proyectos o en la participación en redes con financiación europea-, un determinado modelo administrativo de gestión pública local estaría ya configurando nuevas capacidades institucionales, no asociadas a los títulos competenciales, para las que se precisaría formalización jurídica. Y sin que se hayan producido tampoco cambios en la distribución del poder en el territorio, ni perdido protagonismo, en la acción pública, la lógica jurídico-administrativa. Se estaría transformando, que es la tesis que aquí se viene sosteniendo.

\subsection{Limitaciones derivadas del régimen local}

Desde una perspectiva jurídico-administrativa, estas capacidades institucionales, según se han destacado, tienen la consideración de principios jurídicos que definen el marco conceptual de lo que ha de ser y de cómo deban proceder las Administraciones en un Estado de Derecho, que materializó inicialmente de un

23 «Un modelo estable de reformas incrementales cualitativas y de una paulatina reducción cuantitativa del peso organizativo de la Administración». Alerta RAMIÒ de los riesgos y peligros que tiene este modelo si solo se realizan «pequeños retoques de mejora cualitativa», que serían insuficientes para que el modelo no se decante hacia una gobernanza con una orientación y dominio de carácter privado que colonice los espacios políticos y de gestión públicos por parte de actores económicos privados y, en menor medida, de los actores sociales. Aboga claramente por un modelo de gobernanza con una orientación pública, "ejerciendo la Administración pública la funciones de metagobernador, que ya hemos destacado en el texto, con una función esencialmente reguladora de los diversos ámbitos de convivencia, en directa correlación con el principio del buen gobierno.

24 La Unión Europea, desde hace años, viene haciendo especial énfasis en la promoción de la capacidad institucional de las administraciones en los programas de desarrollo local y urbano. El Objetivo 11 se denomina Mejorar la capacidad institucional de las autoridades públicas y las partes interesadas y la eficiencia de la administración pública. Ver el artículo 9 del Reglamento (UE) núm. 1303/2013 del Parlamento Europeo y del Consejo, de 17 de diciembre de 2013, por el que se establecen disposiciones comunes a los Fondos Europeos. Así, la Comisión Europea (2015) señala que, «apoyar la capacidad administrativa es poner en marcha las estructuras, los recursos humanos, los sistemas y las herramientas adecuados. En otras palabras, garantizar que las responsabilidades y las tareas estén claramente asignadas; el personal correctamente entrenado; y que se contrate a las personas adecuadas para gestionar los fondos. (...) Otro elemento importante es la gobernanza, que supone exigir responsabilidades sobre el rendimiento a los gestores, prevenir la corrupción y el conflicto de intereses, así como fomentar la transparencia».

25 Véase en CASADO et al. (2018: 124-142). En este trabajo se analiza cómo se produce ese impacto, cuál es su naturaleza y en qué medida se implanta en la administración local. 
modo sucinto en el artículo 103.1 de la Constitución ${ }^{26}$. En este marco, la eficacia y la eficiencia estarían ya formando parte del conjunto de capacidades jurídico-institucionales de las administraciones, configurando su razón de ser y marcando el modo en que deben lograr sus fines.

Ambos principios son también inherentes a la esencia misma de la acción local, aunque desde la reforma parcial de la Ley 7/1985, de Bases del Régimen Local, llevada a cabo por la Ley 27/2013, de racionalización y sostenibilidad de la administración local, la eficacia y la eficiencia en la prestación de los servicios públicos y en el ejercicio de actividades económicas -lo mismo que otros principios económicos, como el cumplimiento del periodo de pago a proveedores o de morosidad y la limitación para la concertación de la deuda pública, ahora ligado al principio de prudencia financiera ${ }^{27}$ - se han puesto al servicio de la consecución de dos únicos principios económicos esenciales como son el cumplimiento de la estabilidad presupuestaria y el de sostenibilidad financiera ${ }^{28}$.

El Tribunal Constitucional ha declarado que el principio de estabilidad presupuestaria consagrado en el artículo 135 de la norma fundamental contiene «un mandato constitucional que, como tal, vincula a todos los poderes públicos y que por tanto, en su sentido principal, queda fuera de la disponibilidad -de la competencia- del Estado y de las Comunidades Autónomas», constituyendo, además, «un nuevo canon de constitucionalidad» (sentencia núm. 157/2011, de 18 de octubre de 2011, FJ. $3^{\circ}$ ). En el mismo sentido, el Consejo de Estado ha entendido que «la estabilidad presupuestaria se configura como un límite constitucional, cuya contravención podrá acarrear inconstitucionalidad y nulidad, y también como una orientación constitucionalmente vinculante, que prescribe un programa constitucional obligatorio para la actividad financiera pública» (dictamen núm. 164/2012, de 1 de marzo de 2012).

El texto constitucional reconoce a los entes locales poder financiero, o lo que es igual, poder en materia de ingresos y de gastos públicos, «autonomía para la gestión de sus respectivos intereses». Pero estos eran los aires que soplaban allá por 1978, y que el paso del tiempo ha ido atemperando, renovando sensiblemente la vieja aspiración tendente a la consecución de autonomía financiera local. Pese a que, formalmente, la doctrina jurisprudencial sigue insistiendo en que: "(...) el principio de autonomía financiera de los municipios (arts. 137 y $140 \mathrm{CE}$ ) exige que las Haciendas dispongan de medios financieros suficientes para poder ejercer, sin condicionamientos indebidos, las funciones que legalmente les han sido encomendadas, fundamentalmente, mediante tributos propios (art. $142 \mathrm{CE}$ ), pero que por estar sometidos al principio de reserva de ley (arts. 31.3 y 133.1 y $2 \mathrm{CE}$ ), corresponde al legislador estatal integrar las exigencias derivadas de esa reserva de ley como medio de preservar tanto la unidad del ordenamiento como una básica igualdad de posición de los contribuyentes [STC 233/1999, de 16 de diciembre, FJ 10.c)] (...)"» (Martín, 2019: 16).

El evidente incremento del gasto público local ha ido acompañado también de un notorio incremento de los recursos públicos, pero ese incremento proviene en muy buena medida de recursos cuya titularidad no le corresponde. Puede incluso que tengan una balanza financiera altamente positiva, con superávit presupuestario, con capacidad de financiar gastos urgentes por existencia de remanente de tesorería para gastos generales positivos, escaso nivel de deuda pública local, y que además dispongan en tesorería de un volumen de recursos financieros superior al nivel de deuda pública. Esto efectivamente está sucediendo. Pero la situación es insostenible desde el punto de vista de su autonomía financiera. La reforma del 2013 se inspiró en el cumplimiento de objetivos de naturaleza económica que garantizan un control financiero y presupuestario riguroso

\footnotetext{
26 Véase, sobre el complejo proceso de incorporación del mismo a la Constitución, PAREJO (1989: 15-66), PAREJO (1995: 89152).

27 La regulación de estos principios se encuentran, básicamente, en la siguiente normativa: Ley Orgánica 2/2012 de Estabilidad Presupuestaria y Sostenibilidad Financiera y Real Decreto 1463/2007 reglamento de desarrollo de la Ley 18/2001 de Estabilidad Presupuestaria en su aplicación a las entidades locales (principios de estabilidad, sostenibilidad financiera, de eficacia y de eficiencia). Ley Orgánica 9/2013 de Control de la Deuda Comercial del Sector Público (principio de morosidad).Disposición final trigésimo primera de la Ley 17/2012 y artículo 53 del Texto Refundido de la Ley Reguladora de las Haciendas Locales (principio de límite de endeudamiento). Orden HAP/2075/2014 de 6 de noviembre por el que se establecen los criterios de cálculo del coste efectivo (principio de eficiencia). Real Decreto Ley 17/2014 de Medidas de la Sostenibilidad Financiera delas comunidades autónomas y entidades locales y Resolución de la Secretaria General de Política Financiera de 5 de febrero de 2015 (principio de prudencia financiera).

28 La vigente redacción del artículo 2 LRBRL establece que: «Para la efectividad de la autonomía garantizada constitucionalmente a las Entidades Locales, la legislación del Estado y la de las Comunidades Autónomas, reguladora de los distintos sectores de acción pública, según la distribución constitucional de competencias, deberá asegurar a los Municipios, las Provincias y las Islas su derecho a intervenir en cuantos asuntos afecten directamente al círculo de sus intereses, atribuyéndoles las competencias que proceda en atención a las características de la actividad pública de que se trate y a la capacidad de gestión de la Entidad Local, de conformidad con los principios de descentralización, proximidad, eficacia y eficiencia, y con estricta sujeción a la normativa de estabilidad presupuestaria y sostenibilidad financiera».
} 
por parte del Ministerio de Hacienda, que puede intervenir sobre organización, competencias, presupuestos, formas de gestión y prácticamente cualquier otra cuestión referida a la acción pública local ${ }^{29}$. Con la reforma del año 2013 los municipios de régimen común no tienen prácticamente capacidad económica, y muchos, los de menor población, ni siquiera tienen capacidad de endeudamiento, más allá de la excepcionalidad de las medidas que transitoriamente, con ocasión de la pandemia covid-19, se han adoptado. Solo por esta razón con la reforma se afectó negativamente la capacidad institucional de la Administración local para enfrentar los retos que se asocian a las políticas urbanas, justamente en el sentido opuesto a aquél en que se avanza en la instancia europea. La reforma local que se impulsó no iba dirigida a «más municipalismo» en absoluto. Más bien, involución, debilitando las capacidades institucionales de las entidades locales.

Por otro lado, el establecimiento de las relaciones de colaboración como criterio de actuación que informe la organización administrativa en todas sus vertientes, tiene menos recorrido jurídico, y no está contemplada en el marco conceptual del 103.1 del texto constitucional. En este sentido, la capacidad institucional de la administración local para asumir un enfoque colaborativo sería muy limitada, al venir establecida, exclusivamente, por lo que se deja establecido en tanto que principio aplicable a las relaciones interadministrativas, como deber de actuar con el resto de administraciones públicas para el logro de fines comunes, en los términos de los arts. 141 y 142 LRJSP y 55 y siguientes dela LRBRL. No existe por el contrario un marco general de regulación de la colaboración como principio informante de las relaciones de la administración local con otros actores que no sean administraciones pero que sí deban ser tomados en consideración cuando de gestionar políticas urbanas se trata, en los términos que venimos comentando. Según hemos dicho, la interacción en red de actores diversos, públicos y privados, que se reconocen interdependientes y que actúan conjuntamente para lograr objetivos comunes, son ya una realidad a la que se enfrentan las entidades locales en el transcurso de la ejecución de proyectos financiados con fondos comunitarios. El régimen local solo conoce de fórmulas de colaboración público-privada clásicas (para la gestión indirecta de servicios públicos, para realizar infraestructuras públicas, o para externalizar servicios), pero no de los partenariados público-privados, y cuya existencia forma parte de la nueva metodología para la gestión pública de políticas urbanas en el modelo de desarrollo urbano europeo, según se ha dicho ya. Esto explicaría que la capacidad para asumir un enfoque colaborativo durante la implementación de programas financieros por parte de las entidades locales presente sus mayores índices internamente, entre las distintas áreas administrativas, y no tanto en las relaciones con la sociedad local ${ }^{30}$.

Más allá del aprendizaje que las entidades locales puedan adquiere por esta vía, se echa en falta una regulación que dé sustantividad en el régimen local a estas fórmulas colaborativas; ello repercute de nuevo en la capacidad institucional local para enfrentar los retos que se asocian a las políticas urbanas, para asumir su condición de autoridad urbana, que debería verse normativamente reforzada.

Plurales documentos de naturaleza política que se han conocido en la última década, y con distinto alcance $^{31}$, estarían contemplando la necesidad de cambios en la línea marcada por la Unión Europea. A ello

29 Véase el art. 116 bis, introducido por el número treinta del artículo primero de la Ley 27/2013, 27 diciembre, de racionalización y sostenibilidad de la Administración Local. Implica la subordinación total del municipio, a través de los planes económico-financieros. Por otro lado, como uno de los ingresos fundamentales es su participación en los del Estado mediante unas entregas a cuenta en base a unas previsiones que realiza el Ministerio de Hacienda, hasta que no se conoce el comportamiento real de los ingresos, el Estado procede a la liquidación definitiva, que puede ser positiva o negativa. En el primer caso ingresa la cantidad resultante y en el segundo es el municipio el que debe proceder a la devolución que corresponda. Y aquí es donde aparece uno de los grandes problemas: los Ayuntamientos, al elaborar sus presupuestos, lo hacen en base a unas previsiones de ingresos, entre las que se encuentra esta participación en los del Estado, con unos efectos perversos para la situación económica y financiera municipal si al final resulta una liquidación negativa con la consiguiente devolución al Estado, lo que supone dejar sin cobertura a los gastos ya realizados, sufriendo el municipio una doble penalización: devolver un dinero por un error en la previsión de la que no fue responsable ni tuvo intervención alguna en su cálculo, sin que quien lo cometió asuma ninguna consecuencia, y tener que dotar los gastos que quedan descubiertos. Por no hablar de las subvenciones que reciben, vía por la que se desarrollan, y se financian -dado que tienen que adelantar el importe íntegro de la actuación-, actuaciones que no son de su propia competencia, normalmente es las Comunidades Autónomas, sin que a éstas les cuente como deuda viva ni carga financiera. Una situación económica insostenible con carácter general.

30 Este aspecto queda también reflejado en otros trabajos realizados por HUETE et al. (2016) en torno a este asunto, en los que se señala que el carácter integrado de los programas tiene como consecuencia directa la necesidad de establecer alianzas entre las áreas de la administración con capacidad de decisión sobre las áreas de política pública incluidas en el diseño de la iniciativa. Esto puede deberse al esfuerzo de adaptación al carácter integral de los procesos y de las políticas que se desarrollan en el marco de los programas urbanos europeos, que han de tener en cuenta los distintos sectores involucrados: medioambiental, social, económico, etc. Se observa, sin embargo, que a medida que las administraciones locales van adquiriendo experiencia en la implementación de estos programas, se van entretejiendo cada vez más relaciones con la sociedad local.

31 Entre los que destacan, la Estrategia española de desarrollo sostenible (2006); el Libro Blanco de la sostenibilidad del planeamiento urbanístico español (2008); la Estrategia española de sostenibilidad urbana y local (2012); la Guía Metodológica para los siste- 
se suman recientemente los distintos procesos de «Agendas urbanas» ${ }^{32}$, término frecuentemente empleado como sinónimo de «política urbana». La aprobación de la Agenda Urbana Española en el Consejo de Ministros de 22 de febrero de $2019^{33}$ ha venido a dar cumplimiento al compromiso asumido en el Acuerdo de Asociación de España para el periodo de programación 2014-2020 de los Fondos Europeos. Sin embargo, se ha ido alejando progresivamente de este origen para irse acercando a los Objetivos de Desarrollo Sostenible (ODS) de la Agenda 2030 de Naciones Unidas (Gonzalez, 2019). De este modo, la consideración de la Agenda Urbana Española como una de las 9 «políticas palanca» incluidas en el Plan de Acción para la implementación de la Agenda 2030 para España, le ha otorgado mayor fuerza y visibilidad, pero por ahora solo constituye un hito histórico que exige un firme compromiso político para hacer practicables los cambios.

No encontramos sin embargo en estos documentos una apuesta decidida por el fortalecimiento del gobierno y la administración local para una mejor y más eficaz gestión de políticas urbanas. Sí encontramos en ellos qué es lo que en las ciudades se tiene que hacer, está razonablemente diagnosticado. Ciertamente, las entidades locales ya vienen desarrollando cierto aprendizaje, y asumiendo de manera cada vez más generalizada, y en los más variados asuntos, compromisos acordados voluntariamente en documentos informales y sin efectos jurídicos que van dibujando hojas de ruta que voluntariamente pueden ser aplicadas utilizando los instrumentos normativos y ejecutivos de los que disponen con el actual marco jurídico, en el ámbito de sus competencias ${ }^{34}$. Pero no es suficiente. Por poner un ejemplo, no encontramos en los procesos de «Agendas» referencias sobre cómo afrontar la fragmentación competencial existente, lo cual se refleja en la falta de posicionamiento claro sobre cómo gestionar problemas urbanos clave en los que se interrelacionan los tres principales niveles de gobierno (estatal, autonómico y local), como son la mitigación y adaptación al cambio climático, la eficiencia energética, la vivienda asequible, o la movilidad urbana.

\subsection{El poder de autoadministración de la autonomía local}

En el avance hacia el fortalecimiento institucional de la acción pública local vemos que se requieren capacidades cuya disponibilidad, en el marco jurídico actual del régimen local, o se desatienden o se debilitan, resultando imprescindible replantear los términos que enmarcan una serie de cuestiones que han pautado la propia evolución de los entes locales, como su autonomía. Precisamente, al replanteamiento de los elementos de la autonomía local en su caracterización actual se hace un llamamiento en una reciente Recomendación del Congreso de Poderes Locales y Regionales del Consejo de Europa, de la que se ha hecho eco Font $(2020)^{35}$, para vincularla a objetivos y finalidades. Según señala Font, «la noción de autonomía local según

mas de auditoría, certificación o acreditación de la calidad y sostenibilidad del medio urbano; el Informe de Situación de las principales actuaciones e iniciativas en materia de sostenibilidad urbana en España; el Libro Verde de la sostenibilidad urbana y local en la era de la información; la Red de redes de desarrollo local sostenible; el Sistema municipal de indicadores de sostenibilidad urbana y local (2011).

32 En 2016, Naciones Unidas elaboró la Nueva Agenda Urbana, solo unos meses después del lanzamiento de la Agenda urbana para la UE. En la misma línea, países de todo el mundo han puesto en marcha sus propias agendas, que se presentan como una nueva generación de políticas urbanas que adoptan la forma de marcos estratégicos y se basan en el empleo de instrumentos propios de lo que se conoce como "Nueva Gestión Pública". Véase en GONZÁLEZ (2019).

${ }_{33}$ Accesible en: http://www.exteriores.gob.es/Portal/es/SalaDePrensa/Multimedia/Publicaciones/Documents/PLAN\%20DE\%20 ACCION\%20PARA\%20LA\%2OIMPLEMENTACION\%20DE\%20LA\%20AGENDA\%202030.pdf.

Se trata de un documento de carácter estratégico y voluntario, que incorpora un decálogo de objetivos de desarrollo urbano. Estos objetivos están alineados con las agendas supranacionales, pero sobre todo tienen vocación de inspirar a las agendas impulsadas a nivel autonómico y local. También, se define como un método de trabajo integrado y orientado a la acción, basado en la gestión por objetivos y en la promoción de alianzas entre actores públicos y privados, e incorpora un Plan de acción de la Administración General del Estado para la implementación de la agenda, que contiene una serie de actuaciones dirigidas a avanzar precisamente en el ámbito normativo y de la planificación, la financiación, la gobernanza y en la participación ciudadana, y en el intercambio y difusión de conocimiento. A partir de este punto, la Agenda cede el testigo a las ciudades, a las que provee de una serie de recursos para que puedan realizar por sí mismas su propio Plan de acción. La idea es que este instrumento les ayude a superar las limitaciones del contexto, a promover en su territorio un desarrollo sostenible e integrado y a que se posicionen mejor a la hora de acceder a futuras oportunidades de financiación.

34 Véase entre la abundante bibliografía sobre las redes en que participan las ciudades, propiciadas, cuando no creadas directamente por las instituciones europeas, SARASÍBAR (2011), y AGÜERO (2020).

35 Esta Recomendación, la núm. 429 (2019), de 17 de mayo, titulada La contribution du Congrès à la réflexion sur l'avenir du Conseil de l'Europe, que va acompañada del Anexo Renforcer la démocratie locale et régionale au 21e siècle, hace un llamamiento claro a vincular la Carta Europea de la Autonomía Local a elementos no meramente estructurales de la autonomía local, sino también a objetivos y finalidades a las que tender en ejercicio del poder local, lo cual significaría «una mutación importante de su misma concepción» (FONT 2020). Entre esas nuevas exigencias se citan expresamente las que derivan del Programa de las Naciones Unidas para el desarrollo sostenible, conocido como Agenda 2030. 
REALA. Nueva Época - N.o 14, octubre 2020 - ISSN: 1989-8975 - DOI: https://doi.org/10.24965/reala.i14.10808 - [Págs. 49-68]

Repensar la acción pública local desde nuevos modelos de gestión administrativa

María Rosario Alonso Ibáñez

su concepción europea actual, no es hoy suficiente para hacer frente a las aspiraciones y a las necesidades de las comunidades ciudadanas en las grandes aglomeraciones urbanas que llamamos ciudad», poniendo de manifiesto que el significado mismo de la autonomía local está evolucionando hacia una nueva funcionalidad, no sólo de defensa de derechos y libertades frente al poder del Estado, sino también de instrumento en la lucha por la igualdad social y la solidaridad humana.

Estando de acuerdo con este planteamiento, en la línea que aquí se viene manteniendo, de repensar la acción pública local desde las trasformaciones que conlleva el cada vez más consolidado modelo de desarrollo urbano sostenible, entendemos que se trataría de volver sobre la razón de ser del municipio, lo que le dota de singularidad en ese estar situado "en la frontera difusa entre la sociedad y el Estado» (Parejo, 2011). El municipio institucionaliza la gestión de los asuntos de la colectividad, y la gestión de estos asuntos no es otra cosa que «autoadministración» (Parejo, 2011). La dimensión procedimental o metodológica de la sostenibilidad determina la necesaria transformación de la aproximación a la autonomía local.

Sería esta dimensión metodológica, de gestión, y no tanto la sustancial, la vinculada a los objetivos del desarrollo sostenible, la que daría contenido al poder político de autoadministración, en tanto que dimensión de su autonomía local. O lo que es lo mismo, carecería de sentido limitar la garantía institucional de la autonomía local de los municipios solo a participar, a través de sus órganos propios de gobierno y administración, en cuantos asuntos le atañen, graduándose la intensidad de esa participación en función de la relación existente entre los intereses locales y supralocales en dichos asuntos o materias, como viene señalando la jurisprudencia constitucional ${ }^{36}$. Sería no tomar en consideración que los asuntos que les atañen es algo que no solo está en función de que se haya o no reconocido por el legislador la presencia de intereses locales en determinados asuntos o materias.

Al municipio, institucionalmente, le atañe intervenir en todos los asuntos que afecten a la comunidad local, es su razón de ser; por tanto, no solo en determinados asuntos o materias. Falta incluso la configuración de la sostenibilidad urbana como asunto o materia competencial, algo especialmente difícil, por no decir imposible, en un sistema jurídico que conoce plurales niveles de gobierno territorial, donde la concurrencia competencial forma parte del modelo de Estado querido por la Constitución; y donde falta claridad entre los límites competenciales de las distintas materias concernidas en la sostenibilidad y entre los distintos niveles territoriales implicados. En lo que no hay duda es que en todos los asuntos vinculados con el desarrollo urbano sostenible hay interés local, afectan a la comunidad local.

Esta es la aproximación a la autonomía local presente en la Carta Europea de Autonomía Local, cuando señala en su artículo 3.1 que «Por autonomía local se entiende al derecho y la capacidad efectiva de las entidades locales de ordenar y gestionar una parte importante de los asuntos públicos, en el marco de la Ley, bajo su propia responsabilidad y en beneficio de sus habitantes», y que no es la que ha primado en la jurisprudencia constitucional, sin apenas referencia alguna a la Carta Europea de Autonomía Local. Una jurisprudencia a la que vive encadenado el Tribunal Constitucional, que «no tiene ninguna consistencia, sobre todo por la carta blanca que da a ese legislador básico o al legislador sectorial para modular (al alza o a la baja) el alcance exacto de la autonomía local» (Jiménez, 2013). La dimensión funcional de la autonomía local, tal como ha sido construida por la jurisprudencia constitucional, vinculándola a las competencias locales, que la caracteriza como un núcleo indisponible frente al legislador sectorial, ha desdibujado el componente político de la autonomía local. Además de dejar a los municipios a merced del legislador ordinario, con la sola salvaguarda de la obligación por parte del Estado y de las comunidades autónomas de reservarles «un espacio indeterminado», construido como garantía institucional, pero sin un contenido que proporcione una mínima seguridad jurídica. A nadie se le oculta, como se reconoció expresamente en el Libro Blanco para la Reforma del Gobierno Local (2005: 16), «la vulnerabilidad de esta previsión en un Estado habituado al centralismo y en unas comunidades autónomas en plena fase de afirmación institucional».

Es en el componente político que tiene la autonomía local, el poder de autogobierno, en el que deben considerarse integrados los aspectos metodológicos o de gestión de la sostenibilidad urbana, y de donde

36 Véase la STC 240/2006 de 20 julio, fundamento jurídico segundo: «la autonomía local, tal y como se reconoce en los arts. 137 y $140 \mathrm{CE}$, goza de garantía institucional; lo cual supone el derecho de la comunidad local a participar, a través de sus órganos propios de gobierno y administración, en cuantos asuntos le atañen, graduándose la intensidad de esa participación en función de la relación existente entre los intereses locales y supra locales en dichos asuntos o materias (SSTC 84/1982, de 23 de diciembre; 170/1989, de 19 de octubre). Esta autonomía no tendría sentido alguno si los órganos representativos de la comunidad local no tuvieran las potestades necesarias para su ejercicio (SSTC 84/1982, de 23 de diciembre; 170/1989, de 19 de octubre; 148/1991, de 4 de julio; 46/1992, de 2 de abril). De modo que el reconocimiento de esas potestades es el contenido mínimo (en función de los intereses que debe tutelar) de la garantía institucional de la autonomía local, que como concepto jurídico indeterminado debe concretarse en tiempo y lugar». 
derivar el poder político de los municipios para intervenir en la gestión de todos los asuntos que afecten a la comunidad local. Este poder para intervenir en la gestión de los asuntos de la colectividad es en sí mismo asunto de interés local, al margen de como se ha construido la dimensión funcional de la autonomía local. Se transcendería así también el punto de no retorno en el que legislador del régimen local y el Tribunal Constitucional se han colocado en la búsqueda de cuáles serían las competencias locales indisponibles «en los asuntos que les conciernen». La «recognoscibilidad» de la institución municipal se encontraría en su presencia, proximidad, cercanía a la colectividad local, estando por tanto llamado a intervenir en la gestión de sus asuntos, todos. Por mucho que no pueda, como se ha pretendido doctrinalmente, «establecerse un principio de proporcionalidad o subsidiariedad en favor de la autonomía local» (Baño, 2019).

Se trataría de recobrar el protagonismo político que la Constitución reconoce a los municipios, pero que no se corresponde con la imagen que se ha consagrado en la legislación básica del régimen local. Y es lo que no se ha visto tampoco reconocido en la interpretación constitucional de la capacidad de autogobierno de las entidades locales, que ciertamente, como ha destacado Baño, ha sido generosa, a diferencia de lo ocurrido con las competencias locales. Generosa pero con una limitada visión, reduciendo el poder de autogobierno al plano orgánico -presencia en órganos burocráticos-, al principio representativo, vinculándolo al carácter político del autogobierno local, expresión del carácter democrático netamente afirmado en el art. $140 \mathrm{CE}$ al exigir la elección directa de los concejales mediante sufragio universal, y en virtud del cual el Tribunal Constitucional ha impuesto límites tanto al legislador estatal como al autonómico a la hora de atribuir funciones a órganos de carácter burocrático. No puede concluirse pues, en nuestra opinión, que la autonomía, en su vertiente de autogobierno, se haya cumplido rotundamente tras cuarenta años de democracia.

\section{CONCLUSIONES}

Un nuevo modelo de acción local, adaptada a la sostenibilidad, a su dimensión sustantiva y metodológica, en los términos que en este trabajo se han destacado, pasa necesariamente por la puesta en valor el componente político de la autonomía local.

No se trata de reivindicar un nuevo modelo de gobierno para la ciudad, por mucho que no pueda desconocerse que a las ciudades se las considera, de facto, actores políticamente relevantes. Para algunos autores sería preciso que se configurara la ciudad como nuevo sujeto jurídico-institucional, «una cuestión de extrema necesidad que va a requerir amplios y profundos movimientos de reforma, tanto del derecho nacional como del derecho supraestatal y convencional» (Font, 2020), quien se pregunta si se va a resituar a la ciudad «dentro» del Estado o si se va a colocar a la ciudad «en lugar» del Estado. «En el camino de replantear la autonomía a replantear la soberanía -dice- tal vez esté la respuesta».

Pensamos, sin embargo que no se trataría de pivotar las necesarias reformas jurídicas sobre el concepto de soberanía ${ }^{37}$, sino de redefinir la acción pública local desde el fortalecimiento de las capacidades institucionales, y de la mano de la capacidad de autogobierno de su autonomía local. Desde el fortalecimiento jurídico-institucional de todas sus capacidades, políticas e institucionales, los municipios podrían gestionar una parte sustancial de los asuntos públicos, aquellos que afecten a la comunidad local. En particular, podrían en mejores condiciones ser «autoridades urbanas» en la gestión de las nuevas políticas urbanas, en el sentido que en este trabajo se ha dejado expuesto. Los asuntos de sostenibilidad afectan a la comunidad local, a toda la población en vive en colectividad. Es cuestión de supervivencia.

\section{REFERENCIAS BIBLIOGRÁFICAS}

AGÜERO, B. (2020): "Cambios en la gobernanza global. El rol de las redes de ciudades y los gobiernos locales como promotores del desarrollo sostenible”, en ALONSO IBÁÑEZ, M. R. (dir.): Las Agendas urbanas y el gobierno de las ciudades. Transformaciones, desafíos e instrumentos, págs. 75-90. Madrid: Reus.

37 «Debemos aprender una nueva gramática del poder en un mundo que está constituido más por bienes y males comunes que por intereses exclusivos», dice INNERARITY (2020: 448). Estos intereses no han desaparecido, pero resultan indefendibles fuera del marco del juego común en el que todos estamos implicados, «mientras que el antiguo juego del poder promovía la protección de lo propio y la despreocupación por lo ajeno, la superexposición obliga a mutualizar los riesgos, a desarrollar procedimientos cooperativos, a compartir protocolos, información y estrategias». 
REALA. Nueva Época - N.o 14, octubre 2020 - ISSN: 1989-8975 - DOI: https://doi.org/10.24965/reala.i14.10808 - [Págs. 49-68]

Repensar la acción pública local desde nuevos modelos de gestión administrativa

María Rosario Alonso Ibáñez

ARENILLA, M. (1999): "Las relaciones entre poder y territorio en la vertebración del Estado" en El funcionamiento del Estado autonómico, págs. 89-125. Madrid: Ministerio de Administraciones Públicas.

AUBY, J. B. (2013): La Globalización, el Derecho y el Estado. Sevilla: Global Law Press.

BAÑO LEÓN, J. M. (2019): “Autonomía y competencias locales”, en Documentación Administrativa, núm. 6, págs. 8-15. DOI: $h$ ttps://doi.org/10.24965/da.i6.10761.

BELLET SANFELIU, C. (2020): "Las políticas urbanísticas municipales en España: 40 años de ayuntamientos democráticos (1979-2019)", en Boletín de la Asociación de Geógrafos Españoles, núm. 85, págs.1-38. DOI: https://doi.org/10.21138/bage.2877.

BLANCO, I.; SUBIRATS, J. (2012): "Políticas urbanas en España: Dinámicas en transformación y retos urbanos ante la crisis", en Geopolitica(s), vol. 3, núm. 1. Monográfico. págs. 15-33. DOI: https://doi.org/10.5209/rev_GEOP.2012. v3.n1.39304.

BORJA, J. (2011): “Ciudades del mañana. Derecho a la ciudad y democracia real”, en Revista Digital (Café de las Ciudades), Año 10, núm. 108, octubre 2011. Buenos Aires: Editorial Café de las Ciudades.

CASADO, M.; HUETE, M. A.; MERINERO, M.; GONZÁLEZ MEDINA, M. (2018): "La influencia de la iniciativa URBANA 2007-2013 en el desarrollo de la capacidad institucional de la administración municipal", en Gestión y Análisis de Políticas Públicas, Nueva Época, vol. 10, núm. 20, págs. 124-142. Número monográfico Gobernanza y políticas de desarrollo urbano: teoría y práctica. DOI: https://doi.org/10.24965/gapp.v0i20.10487.

CASSESE, S. (2015): "Global administrative law: The state of the art", en International Journal of Constitutional Law, vol. 13, núm. 2, págs. 465-468. DOI: https://doi.org/10.1093/icon/mov022.

DE GREGORIO HURTADO, S. (2017): "Is EU urban policy transforming urban regeneration in Spain? Answers from an analysis of the Iniciativa Urbana (2007-2013)", en Cities, núm. 60, págs. 402-414. DOI: https://doi.org/10.1016/j. cities.2016.10.015.

DE GREGORIO HURTADO, S. (2020): "Conviven dos agendas urbanas en la Unión Europea? La Agenda Urbana Europea versus el Acervo Urbano”, en ALONSO IBÁÑ̃Z, M. R. (dir.): Las Agendas urbanas y el gobierno de las ciudades. Transformaciones, desafíos e instrumentos, págs. 120-134. Madrid: Reus.

FARINÓS DASÍ, J. (2015): "Planificación territorial y desarrollo local, y su relación con las nuevas formas de gobernanza territorial asociadas", en NOGUERA TUR, J. (coord.): La visión territorial y sostenible del desarrollo local. Una perspectiva multidisciplinar, págs. 67-92. Valencia: Universidad de Valencia. Servicio de Publicaciones.

FONT I LLOVET, T. (2020): "De la autonomía local al poder de las ciudades", en Anuario del Gobierno Local 2020. Barcelona: Fundación Democracia y Gobierno Local.

GONZÁLEZ MEDINA, M. (2018): "Del enfoque integrado de desarrollo urbano sostenible de la Unión Europea al paradigma de la gobernanza urbana en España”, en ALONSO IBÁÑEZ, M. (dir.): Retos del desarrollo urbano sostenible e integrado, págs. 35-64. Valencia: Tirant.

GONZÁLEZ MEDINA, M. (2019): “La Agenda Urbana Española, ¿oportunidad u oportunismo?”, en Blog idl UAM. Madrid: Instituto de Derecho Local-UAM. Fecha de consulta: 20-03-2019. URL: https://www.idluam.org/b/og/laagenda-urbana-espanola-oportunidad-u-oportunismo/.

IGLESIAS, M., MARTÍ-COSTA, M., SUBIRATS, J.; TOMÀS, M. (2011): Políticas urbanas en España Grandes ciudades, actores y gobiernos locales, Madrid: Icaria.

INNERARITY, D. (2020): Una teoría de la democracia compleja: Gobernar en el siglo XXI. Madrid: Galaxia Gutenberg.

JIMENEZ ASENSIO, R. (2013): "Llei de modernització i règim local: una perspectiva constitucional", en Jornada sobre la funció pública directiva a les entitats locals. Barcelona, 27 de abril de 2004. Escola d’Administració Pública de Catalunya.

JIMENEZ ASENSIO, R. (2016): "La (primera) sentencia del tribunal constitucional sobre la "reforma local", en Blog La mirada institucional, Fecha de consulta: 09-03-2016. URL: https://rafaeljimenezasensio.com/2016/03/09/laprimera-sentencia-del-tribunal-constitucional-sobre-la-reforma-local/.

MARCHECO ACUÑA, B. (2018): "Los desafíos de la ciencia del Derecho administrativo ante la globalización", en Revista General de Derecho Administrativo, núm. 49, págs. 59-70.

MARTIN QUERALT, J. (2020): “Autonomía financiera local”, en Documentación Administrativa, núm. 6, págs. 16-25. DOI: $h$ ttps://doi.org/10.24965/da.i6.10762.

PINSON, G. (2011): Urbanismo y gobernanza de las ciudades europeas. Gobernar la ciudad por proyecto, Tesis Doctoral. Valencia: Universidad de Valencia.

PAREJO, L. (2011), "Breve reflexión sobre la Administración local hoy (expuesta con ocasión de la presentación de la $3^{a}$ edición del Tratado de Derecho Municipal dirigido por S. Muñoz Machado)", en Asociación Española de profesores de Derecho Administrativo. URL: http://www.aepda.es/AEPDAPublicaciones-180-.

PAREJO ALFONSO, L. (1989): "La eficacia como principio jurídico de actuación de la Administración Pública", en Documentación Administrativa, núm. 218-219, págs. 15-66. DOI: https://doi.org/10.24965/da.v0i218-219.5132.

PAREJO ALFONSO, L. (1995): "La eficacia, principio de la actuación de la Administración", en Eficacia y Administración. Tres estudios, págs. 89-152. Madrid: BOE; INAP.

RAMIÒ, C. (2016): "La gran impostura: la reforma política e institucional de la Administración pública en España", en El Blog de esPúblico, Zaragoza: Fundación ESPUBLICO. Fecha de consulta: 29-03-2016. URL: https://www. administracionpublica.com/la-gran-impostura-la-reforma-politica-e-institucional-de-la-administracion-publica-en-espana/. 
REALA. Nueva Época - N.o 14, octubre 2020 - ISSN: 1989-8975 - DOI: https://doi.org/10.24965/reala.i14.10808 - [Págs. 49-68]

Repensar la acción pública local desde nuevos modelos de gestión administrativa

María Rosario Alonso Ibáñez

RAMIÒ, C. (2017): La Administración pública del futuro (horizonte 2050). Instituciones, política, mercado y sociedad de la innovación, págs. 1-248. Madrid: Tecnos.

RAMIÓ, C. (2020): "La renovación de la colaboración público privada I: Diagnóstico". "La renovación de la colaboración público privada II: Propuestas", en El Blog de esPúblico. Zaragoza: Fundación ESPUBLICO, Fecha de consulta: 01-04-2020. URL: https://www.administracionpublica.com/la-renovacion-de-la-colaboracion-publico-privada-iipropuestas/.

SARASÍBAR IRIARTE, M. (2011): "La participación de las entidades locales en los ámbitos estatal y supranacional”, en Revista Vasca de Administración Pública, núm. 89, págs. 149-181.

SIMOU, S. (2020), Derecho local del cambio climático, págs. 21-28. Madrid: Marcial Pons.

SUBIRATS, J.; MARTÍ-COSTA, M. (2015): "Conclusiones”, en SUBIRATS, J.; MARTÍ-COSTA, M.: Ciudades y cambio de época: discursos sobre políticas urbanas y crisis en España. Bilbao: Servicio Editorial de la Universidad del País Vasco/Euskal Herriko Unibertsitateko Argitalpen Zerbitzua.

VELASCO CABALLERO, F. (2020): "Prólogo", en SIMOU, S.: Derecho local del cambio climático. Madrid: Marcial Pons.

YSA, T. (2004): "Riesgos y beneficios de trabajar en partenariado en los gobiernos locales", en IX Congreso Internacional del CLAD sobre la Reforma del Estado y de la Administración Pública. URL: http://biblioteca. municipios.unq.edu.ar/modules/mislibros/archivos/0049630.pdf. 